\title{
A Novel Ionic Liquid for Carbon Capture
}

\author{
By Amita Chaudhary ${ }^{*}$ \\ Ashok N. Bhaskarwar
}

\begin{abstract}
Many chemical processes require use of a solvent. Due to the adverse environmental effects of volatile organic compounds (VOCs), there is a need for replacement of traditional volatile solvents and hence a rising interest among researchers in the field of non-volatile solvents. A large number of chemical reactions are carried out in the presence of a solvent. Recently, a new class of non-volatile solvents has emerged called ionic liquids. An ionic liquid is an organic salt mainly composed of ions which are poorly coordinated, resulting in a low melting point often below $100^{\circ} \mathrm{C}$. It consists of an organic or an inorganic bulky cation and a smaller anion. Due to the unsymmetrical ions, the lattice energy and the melting point of the ionic liquids are lower than of inorganic salts. Ionic liquids have many unique properties, such as high thermal stability, large oxidative and reductive range, good solvent for most of the organic and inorganic solutes, non-corrosive and corrosion-preventing nature, high ionic conductivity, and negligible vapour pressure. Their properties can be tailored, and hence ionic liquids have also been termed as the "designer solvents". Ionic liquids can broadly be categorized into protic and aprotic ionic liquids. We have synthesized, and filed a patent on a new low-cost ammonium-based protic ionic liquid by solvent-free acid-base neutralization method. Its physicochemical properties like viscosity and density, and their variation with temperature have been measured, as well as its thermal stability quantified. Its application in carbon capture, considering its great affinity towards the CO2 molecules, has also been explored. Effect of interaction of water molecules with the ionic liquid on its absorption capacity for $\mathrm{CO} 2$ has also been assessed. It is found that this novel ionic liquid has the highest absorption capacity to cost ratio compared to all ionic liquids reported to date.
\end{abstract}

Keywords: Absorption capacity, CO2, Density, Green solvent, Protic ionic liquid (PIL), Viscosity.

\section{Introduction}

Over the last two decades, alarming temperature increase due to continuous increase in carbon dioxide concentration in the atmosphere has shown serious repercussions for the environment and mankind. Researchers, scientists, and environmentalists are all expressing concern over changes in the overall climate. Researchers are in search of better solvents or better technologies to capture the carbon dioxide. Large part of the carbon dioxide emission is from the combustion of fossil fuels like coal in power- generating plants. The technologies used for capture of carbon dioxide from flue gases

*Research Scholar, Indian Institute of Technology, India.

${ }^{\dagger}$ Professor, Indian Institute of Technology, India. 
are: absorption, adsorption, membrane separation/permeation, and cryogenic distillation. Out of these technologies, absorption is widely used at large scale due to its low cost and energy-efficient merits. Commercially, amines and alkanol amines are used for scrubbing carbon dioxide in post combustion-based carbon-capture systems. Over a period, ionic liquids are likely to emerge as the best green-solvents which have wide range of applications due to their unique properties. Ionic liquids are salts which have low melting points $\left(<100{ }^{\circ} \mathrm{C}\right)$. They exhibit high solubility and selectivity for carbon dioxide, especially at a high pressure and at room temperature. Ionic liquids are non-flammable and non-volatile (Maginn, 2005). The decomposition temperature is generally above $300{ }^{\circ} \mathrm{C}$. Ionic liquids have negligible vapour pressures selectively capturing carbon dioxide from a mixture of gases (Bates, 2002). In the past decade, conventional ILs, such as those based largely on imidazolium, pyrrolidinium or ammonium cation coupled with large anions with delocalised or sterically hindered charge, have been intensively investigated for $\mathrm{CO}_{2}$ capture by a physical absorption mechanism (Yokozeki, 2008). The effect of the anion on the solubility of carbon dioxide for imidazolium based ionic liquids has been studied and the results indicate that, in the case of anions containing fluorinated alkyl groups, a strong interaction with carbon dioxide is responsible for the higher solubility (Scovazzo, 2004). Yokozeki and Compton researcher proved that ionic liquid having acetate anion shows better absorption capacity of carbon dioxide in compare to the purely physical absorption of $\mathrm{CO}_{2}$ by many RTILs (Room Temperature Ionic Liquids) (Barrosse-Antle \& Compton, 2009). Hence, attention has been more focused on tailoring the sites of ions with more basic functionalized group having the capability of chemically binding with carbon dioxide. Davis and co-workers studied an ionic liquid consisting of an imidazolium cation, tetra fluoro borate anion with amine functionality was having the absorption capacity of 0.5 mole of carbon di-oxide per mole of ionic liquid (Aki, 2006). With primary and secondary amine the theoretical maximum absorption can reach up to 0.5 mole of carbon di-oxide per mole of amine. Wang and co-workers (2010) got enhanced equi-molar reversibly absorption capacity by using super-base derived ionic liquids. Yang et al. (2011) also described task specific ionic liquids having amine for carbon dioxide capture, while Galan Sanchez (2007) employed that, amine functionalized ionic liquid shows thirteen times higher solubility then non-amine functionalized ionic liquids. In post-combustion system, large amount of solvent is required to treat the carbon di-oxide at low pressure. Conventional ionic liquids are costly and exhibit relatively low absorption capacities at low pressure (Astarita, 1983). Another challenge with ionic liquid is their high viscosities. Due to the columbic interactions among the ionic liquid constituents contribute to the high viscosity of ionic liquids. The carbon dioxide adducts with amine further increases the viscosity due to the presence of hydrogen bonding between them results in high mass-transfer resistance (Tsuzuki et al., 2009). High cost and slow rates of absorption and desorption process make it unsuitable for a large-scale application. 
The objective of the present study was, therefore, to explore the carbon dioxide absorption capacity of new low-cost protic ionic liquid (PIL) containing multi-amine functionalized sites. Protic ionic liquids are produced by proton transfer from a Bronsted acid to a Bronsted base. Ionic liquid used in this study was composed of two primary and two secondary amine groups. Due to the more basic nature of secondary amine, the proton removed from an acid is going to attach with the secondary-amine nitrogen. It is found that by converting the existing amines and alkanolamine solvents into ionic form by protonation technique avoided the evaporative loss of solvent at elevated temperatures. The protic ionic liquid (PIL) investigated in this study is a novel ionic liquid TETAL shown in Figure 1. The PIL TETAL was made as per the literature procedure (Wasserscheid \& Welton, 2003). The structure of synthesized IL has been elucidated on the basis of FT-IR, ${ }^{1} \mathrm{H}$ NMR, ${ }^{13} \mathrm{C}$ NMR and mass spectroscopy. The solubility of carbon dioxide into the reaction mixture was measured by volumetric titration. The capacities of carbon dioxide uptake at the ambient conditions, i.e. 1 atmospheric pressure and $298 \mathrm{~K}$ for both neat and the different $\mathrm{v} / \mathrm{v} \% \mathrm{~s}$ of aqueous solutions of TETAL were investigated. The results are shown in Figure 12. Industrial carbon dioxidecapturing systems mostly use $30 \% \mathrm{w} / \mathrm{w}$ aqueous solutions of conventional solvents. We also investigated the carbon dioxide absorption in $0.7 \mathrm{M}$ aqueous solutions of TETAL for 70 hours in temperature and pressure controlled experiments.

\section{Reactions Pathways}

In an amine- based carbon dioxide capturing plant, the primary and secondary amines are converted into carbamate salt upon absorbing carbon dioxide.

$$
\begin{aligned}
& \mathrm{RNH}_{2}+\mathrm{CO}_{2} \longrightarrow \mathrm{RNHCOO}^{-}+\mathrm{H}^{+} \\
& \mathrm{R}_{2} \mathrm{NH}+\mathrm{CO}_{2} \longrightarrow \mathrm{R}_{2} \mathrm{NCOO}^{-}+\mathrm{H}^{+}
\end{aligned}
$$

The reaction of $\mathrm{CO}_{2}$ with tertiary amines results in the formation of a bicarbonate salt.

$$
\mathrm{R}_{3} \mathrm{~N}+\mathrm{CO}_{2}+\mathrm{H}_{2} \mathrm{O} \longrightarrow \mathrm{R}_{3} \mathrm{NHCO}_{3}{ }^{-}+\mathrm{H}^{+}
$$

In the reaction mixture, nine main species are present: precursor amines $\left(\mathrm{RNH}_{2} / \mathrm{R}_{2} \mathrm{NH} / \mathrm{R}_{3} \mathrm{~N}\right)$, protonated amines $\left(\mathrm{amH}^{+}\right)$, carbamates $\left(\mathrm{RNHCOO}^{-}\right.$, $\left.\mathrm{R}_{2} \mathrm{NCOO}^{-}\right)$, carbonate $\left(\mathrm{CO}_{3}{ }^{2-}\right)$, bicarbonate $\left(\mathrm{R}_{3} \mathrm{NHCO}_{3}{ }^{-}\right)$, hydronium ion $\left(\mathrm{H}_{3} \mathrm{O}^{+}\right)$, hydroxyl ion $\left(\mathrm{OH}^{-}\right), \mathrm{CO}_{2}$, and water.

The reaction between carbon dioxide and amines took place either by a two-step zwitterion mechanism (Caplow, 1968; Danckwerts, 1979) or by a single-step termolecular mechanism (Crooks, 1989). 


\section{Zwitterion Mechanism}

In this mechanism, zwitterion is formed as an intermediate in the reaction between carbon dioxide and amine:

$$
\mathrm{CO}_{2}+\mathrm{R}_{2} \mathrm{NH} \leftrightarrow \mathrm{R}_{2} \mathrm{~N}^{+} \mathrm{HCOO}^{-}
$$

This zwitterion undergoes de-protonation by a base B like water, amine, $\mathrm{OH}^{-}$etc and results in carbamate formation:

$$
\mathrm{R}_{2} \mathrm{~N}^{+} \mathrm{HCOO}^{-}+\mathrm{B}: \rightarrow \mathrm{R}_{2} \mathrm{NCOO}^{-}+\mathrm{BH}^{+}
$$

Due to the low stability of carbamate, it readily undergoes hydrolysis forming bicarbonates and releasing free amine molecules. The regenerated amine again reacts with carbon dioxide. Initially the carbamate species are dominant and later corresponding quantities of bicarbonate ions can be confirmed by ${ }^{13} \mathrm{C}$ NMR.

The contributions of the three reactions of carbon dioxide with water to the overall rate are assumed to be negligible on account of low solubility of carbon dioxide in water.

At steady state, the overall reaction rate between carbon dioxide and aqueous solution of amine can be expressed as

$$
R_{\mathrm{CO}_{2}}=\frac{k_{2}\left(\mathrm{CO}_{2}\right)\left(R_{2} \mathrm{NH}\right)}{1+\frac{k_{-1}}{k_{B}(B)}}
$$

As here,

$\mathrm{k}_{2}=$ second-order reaction rate constant, $\mathrm{L} \cdot \mathrm{mol}^{-1} \cdot \mathrm{s}^{-1}$

$\mathrm{k}_{-1}=$ backward rate constant, $\mathrm{s}^{-1}$ and

$\mathrm{k}_{\mathrm{B}}=$ the kinetic constant representing the de-protonation of the zwitterion by any base, $\mathrm{s}^{-1}$.(Vaidya, 2007)

\section{Termolecular Mechanism}

The termolecular mechanism proposed by Crooks and Donnellan (1989) assumes that the amine reacts simultaneously with one molecule of carbon dioxide and one molecule of a base. The reaction proceeds in a single step via a loosely-bound encounter complex as the intermediate rather than a zwitterion.

$$
\mathrm{R}_{2} \mathrm{NH}+\mathrm{CO}_{2}+\mathrm{H}_{2} \mathrm{O} \leftrightarrow \mathrm{R}_{2} \mathrm{~N}^{+} \mathrm{COO}^{-} \ldots . . . \mathrm{BH}^{+} \mathrm{H}_{3} \mathrm{O}^{+}
$$

When water is the base then the reaction is first order with respect to the initial concentration of amine.

$$
R_{\mathrm{CO}_{2}}=k_{\mathrm{H}_{2} \mathrm{O}}\left(\mathrm{H}_{2} \mathrm{O}\right)\left(\mathrm{CO}_{2}\right)(\text { Amine })
$$
be

As carbon dioxide reaction with water is negligible, the rate equation will

$$
R_{\mathrm{CO}_{2}}=k^{\prime}\left(\mathrm{CO}_{2}\right)(\text { Amine })
$$


As here,

$\mathrm{k}^{\prime}=k_{\mathrm{H}_{2} \mathrm{O}} \cdot\left(\mathrm{H}_{2} \mathrm{O}\right)$

\section{Experimental Work}

\section{Chemicals}

All chemicals used in the experiments were of analytical grade. Triethylene tetramine (TETA, CDH), Lactic acid (LOBA CHEMIE), concentrated hydrochloric acid (Sigma Aldrich), methyl orange indicator (Sigma Aldrich) were used without purification. Carbon dioxide $\left(\mathrm{CO}_{2}\right.$, 99.99\%) and nitrogen $\left(\mathrm{N}_{2}, 99.99 \%\right)$ gases were purchased from Sigma Aldrich. Purity of gases was checked by ULTIMA-2100 series gas chromatograph of Nettle make. All solutions were prepared using de-ionised water in volumetric glassware.

\section{Synthesis of [Triethylene tetrammonium] [Lactate]}

Equi-molar quantities of triethylenetetramine and lactic acid were taken in a three -necked round bottom flask equipped with a reflux condenser, a pressure funnel, and a mechanical stirrer. Initially, triethylenetetramine was taken in the round bottom flask and then lactic acid added drop by drop using a pressure funnel with constant stirring at $120 \mathrm{rpm}$ using the mechanical stirrer. As the neutralization reaction produces a lot of heat, which is equal to $-9 \mathrm{kcal} /$ mol, the round bottom flask was kept in an ice-water mixture. To avoid any contamination with air, the reaction mixture was placed under $\mathrm{N}_{2}$ atmosphere. It was then stirred for several hours at room temperature. The completion of reaction was monitored by TLC. The product was a pale yellow viscous liquid. Product was then washed with dichloromethane 2-3 times to remove impurities. Residual water is removed by vacuum heating at $80{ }^{0} \mathrm{C}$ for 12 hours. The ionic liquid was finally stored-in an air tight flask. The water content of the ionic liquid was analysed using the TGA analysis and found to be $0.01 \%(\mathrm{w} / \mathrm{w})$.

Proposed Reaction and Mechanism
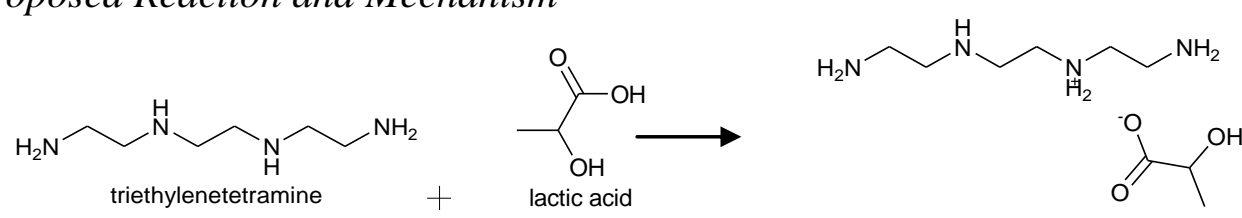

[Triethylenetetrammonium][Lactate] 
Figure 1. Mechanism of Reaction
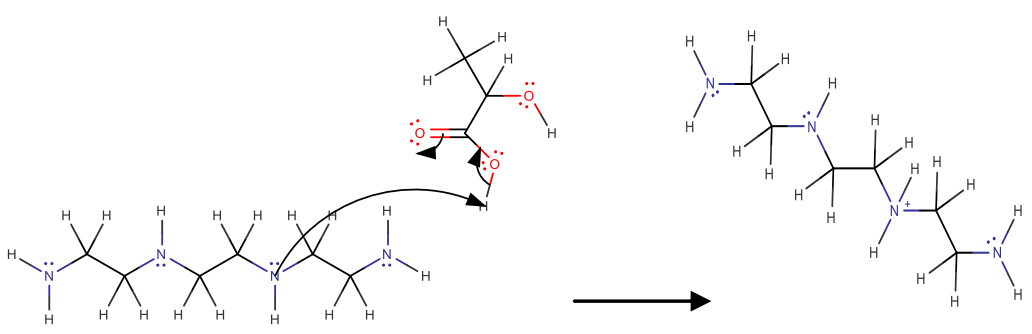

Protonated amine

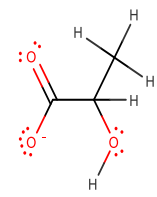

Deprotonated acid

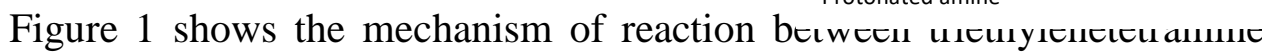
(TETA) and lactic acid.

\section{Characterization}

The structure of synthesized protic ionic liquid was elucidated using FTIR, ${ }^{1} \mathrm{H}$ NMR, ${ }^{13} \mathrm{C}$ NMR, and Mass spectroscopy.

\section{FT-IR Data}

IR spectra of triethylenetetrammonium lactate before (Figure 2) and after the carbon dioxide absorption (Figure 3) were compared for identification of changes due to carbon-dioxide absorption is given in Table 1.

Table 1. FT-IR Data

\begin{tabular}{|l|c|}
\hline \multicolumn{1}{|c|}{ Compound Type } & Frequency range $\left(\mathrm{cm}^{-1}\right)$ \\
\hline $\begin{array}{l}\mathrm{C}=\mathrm{O} \text { asymmetric stretching } \\
\text { band of carbamate }\end{array}$ & 1734 \\
\hline $\begin{array}{l}\mathrm{C}-\mathrm{N} \text { stretching band of } \\
\text { carbamate }\end{array}$ & 1408.93 \\
\hline $\begin{array}{l}\mathrm{C}=\mathrm{O} \text { symmetric stretching } \\
\text { band of carbamate }\end{array}$ & 1125.45 \\
\hline $\mathrm{C}-\mathrm{N}$ stretching band & 1262 \\
\hline $\mathrm{COO}^{-}$symmetric stretch & 1383 \\
\hline $\mathrm{NH}_{3}{ }^{+}$bending & 1460 \\
\hline
\end{tabular}

Figure 2. FT-IR of Neat Triethylenetetrammonium Lactate without Absorbing Carbon Dioxide

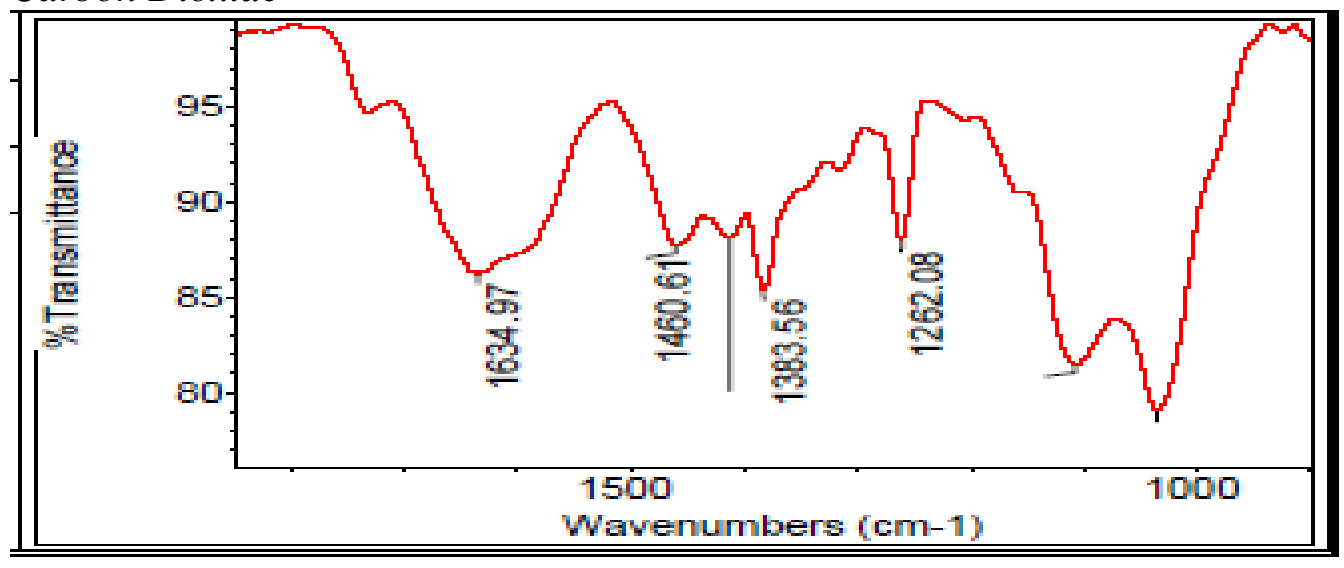


Figure 3. FT-IR of Neat Triethylene Tetrammonium Lactate after Absorbing Carbon Dioxide

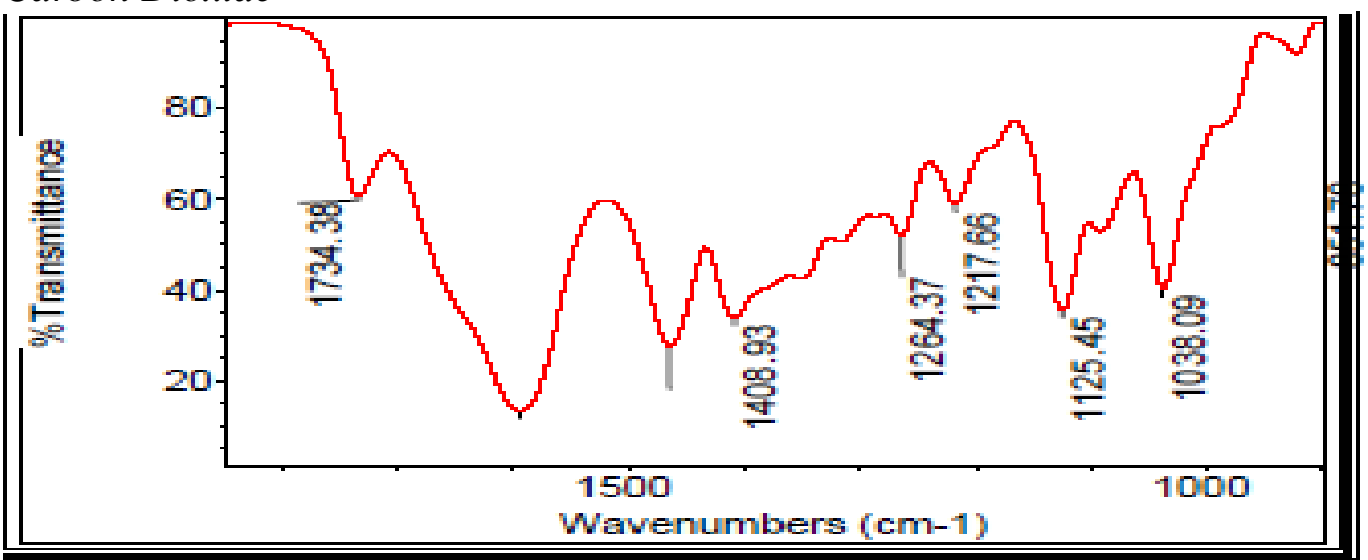

NMR Measurement

Qualitative ${ }^{1} \mathrm{H}$ and ${ }^{13} \mathrm{C}$ NMR experiments for molecular- structural determination were run at room temperature using a Bruker $300 \mathrm{MHz}$ spectrometer. An NMR sample of TETAL was prepared in deuterated DMSO$\mathrm{d}_{6}$. To avoid any disturbance between the deuterated solvent and the analyzed mixture, a capillary tube was use to load DMSO- $\mathrm{d}_{6}$ with the sample in NMR tube. The residual proton in DMSO- $\mathrm{d}_{6}$ was used as the ${ }^{1} \mathrm{H}$ NMR external reference at $2.50 \mathrm{ppm}$. The proton present in Triethylenetetrammonium Lactate in different environment is shown in Figure 4.

Figure 4. ${ }^{1} H$ NMR of Triethylene tetraammonium Lactate

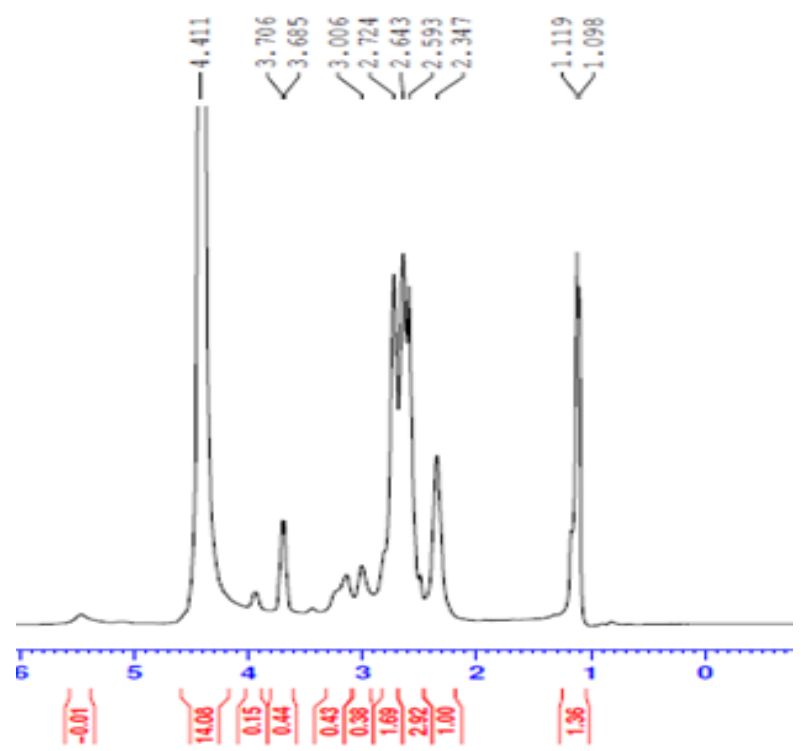

${ }^{13} \mathrm{C}$ NMR spectra were obtained for the neat TETAL and after absorbing carbon dioxide in order to investigate the nature of the carbon dioxide bound species being formed. There was no signal for the carbamate carbon around 
159-165 ppm in neat TETAL. In carbon di-oxide absorbed TETAL sample a signal is observed at $163.54 \mathrm{ppm}$ that is attributed to the carbamate carbon (Figure 5(a) \& Figure 5(b)).

${ }^{13} \mathrm{C}$ NMR: $\delta \mathrm{C}\left(300 \mathrm{MHz}\right.$; DMSO-d $\left.{ }_{6}\right) 39.5 \mathrm{ppm}$ : For Lactate ion: 179.38($\mathrm{COOH}), 67.68(-\mathrm{CHOH}), 22.1\left(\mathrm{CH}_{3}\right)$; TETA ion: $40,45,50\left(\mathrm{CH}_{2} \mathrm{~N}, \mathrm{NH}_{2}, \mathrm{NH}\right)$

${ }^{1} \mathrm{HNMR}: \delta \mathrm{H}\left(300 \mathrm{MHz}\right.$; DMSO-d $\left.{ }_{6}\right): 1.119$ (s, 3H, $\mathrm{CH}_{3}$ ), 2.347, 2.724, 2.593 $\left(\mathrm{CH}_{2} \mathrm{~N}\right), 4.4$, (br s, $\left.\mathrm{NH}, \mathrm{NH}_{2}\right)$;

Figure 5. (a) ${ }^{13 C}$ NMR of Triethylene tetrammonium Lactate (a)

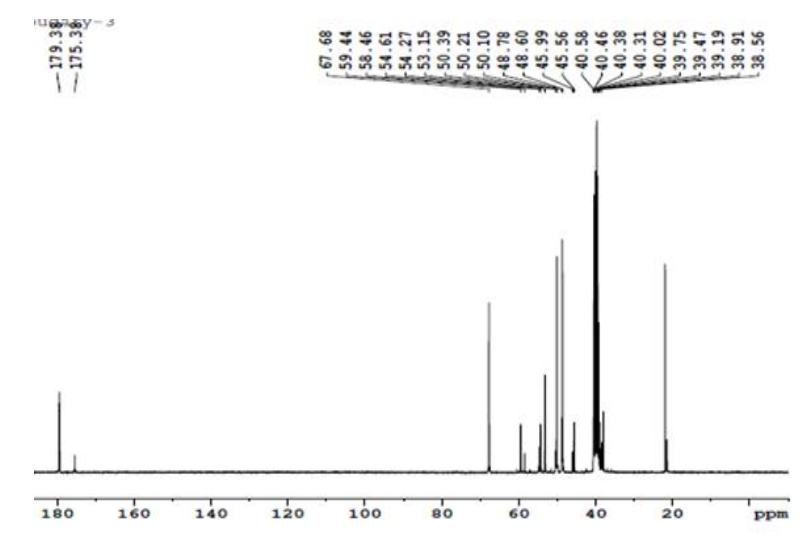

(b) ${ }^{13}$ C NMR of Triethylenetetrammonium Lactate with Carbon Dioxide

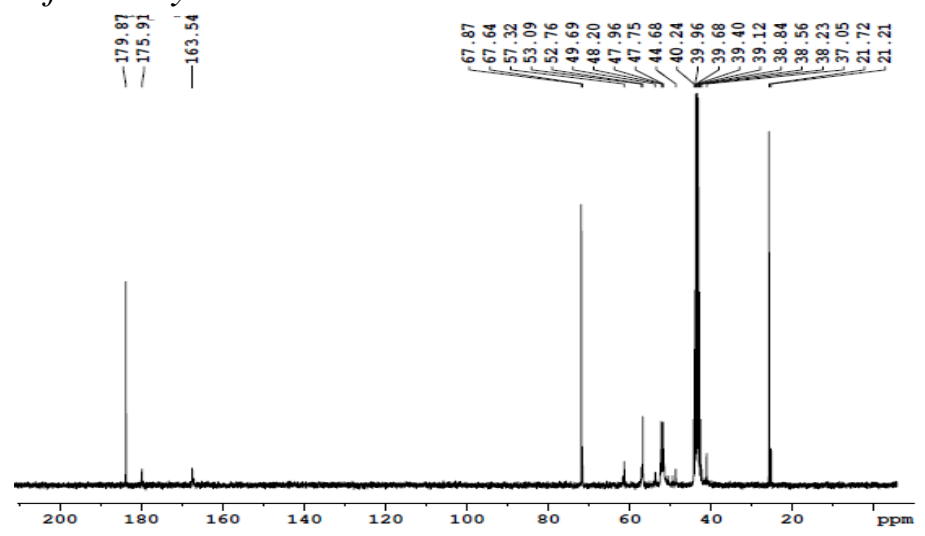


Figure 6. Mass Spectrum of triethylenetetrammonium Lactate
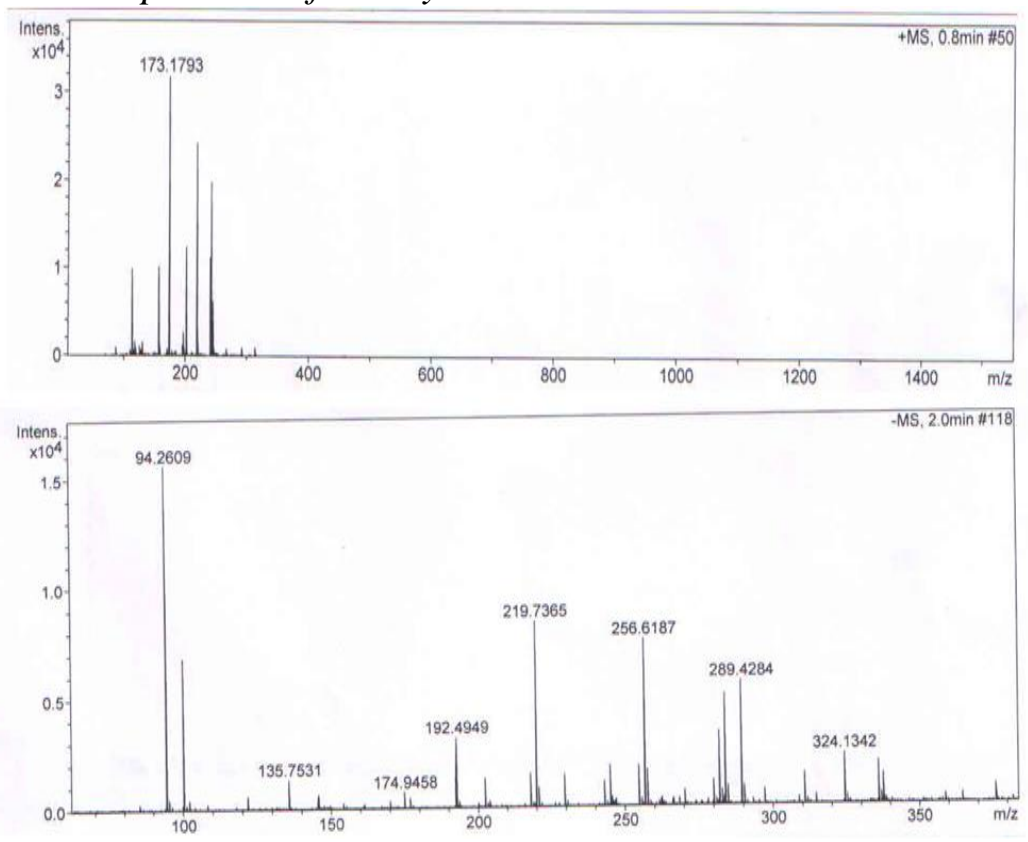

The molecular mass of Triethylenetetrammonium Lactate is $244.44 \mathrm{~g}$ mole ${ }^{-1}$ depicted from the mass spectrum of TETAL in Figure 6.

\section{Physicochemical Properties}

\section{Thermal Stability}

Thermogravimetric analysis (TGA) was performed using a Thermo Gravimetric Analyzer of Netzsch Instruments under a nitrogen atmosphere. The samples were weighed, and then heated from room temperature to $300{ }^{\circ} \mathrm{C}$ at a ramping rate of $10^{\circ} \mathrm{C} \cdot \mathrm{min}^{-1}$. TGA analysis for the pure TETAL shows that the sample is stable and does not loss weight until $150{ }^{\circ} \mathrm{C}$, Figure 7 indicating that TETAL is more stable than the corresponding polyamine TETA as a result of the salt formation. 
Figure 7. Thermogravimetric Analysis of Triethylenetetrammonium Lactate

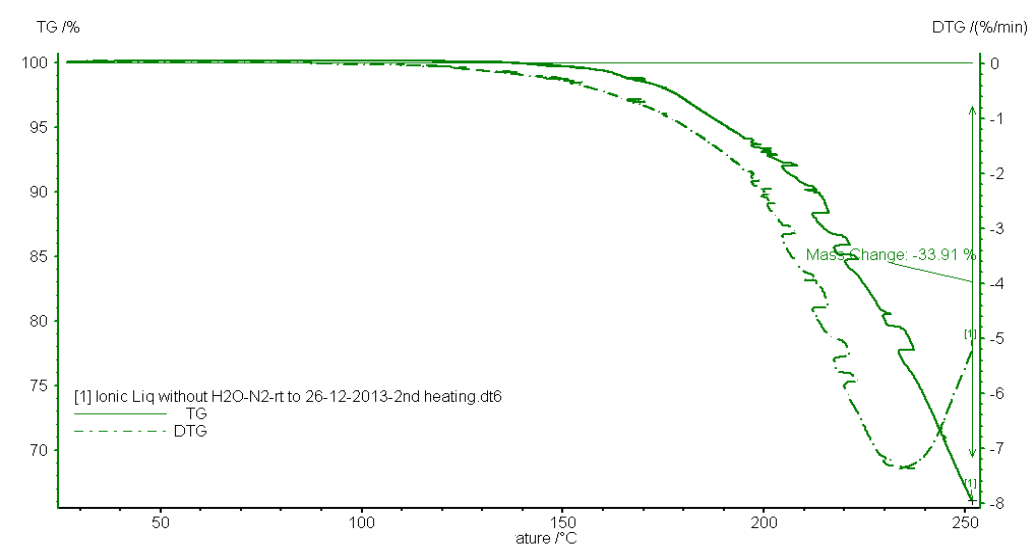

Viscosity

The dynamic viscosity was measured for the system TETAL as a function of temperature from 273 to $388 \mathrm{~K}$ using Anton Paar MCR302 SN81193479. Watanabe et al. (Tsuzuki et al., 2009) reported that the three main factors for viscosity of ionic liquids are size, shape, and interaction between the anion and the cation. The interaction forces between anion and cation are columbic forces, van der Waals forces, and hydrogen-bonding. Out of these forces in neat ionic liquid the columbic forces are responsible and in carbon dioxide absorbed ionic liquid hydrogen-bonding mainly cause viscosity. The viscosity of ionic liquid directly influences the diffusivity of ions in the solution. The experimental viscosity of TETAL as a function of temperature is given by Figure 8:

$\eta($ Pa.s $)=1 \times 10^{6} \mathrm{e}^{-0.047 \mathrm{~T}(\mathrm{~K})}$

Figure 8. Variation of Viscosity of TETAL with Temperature

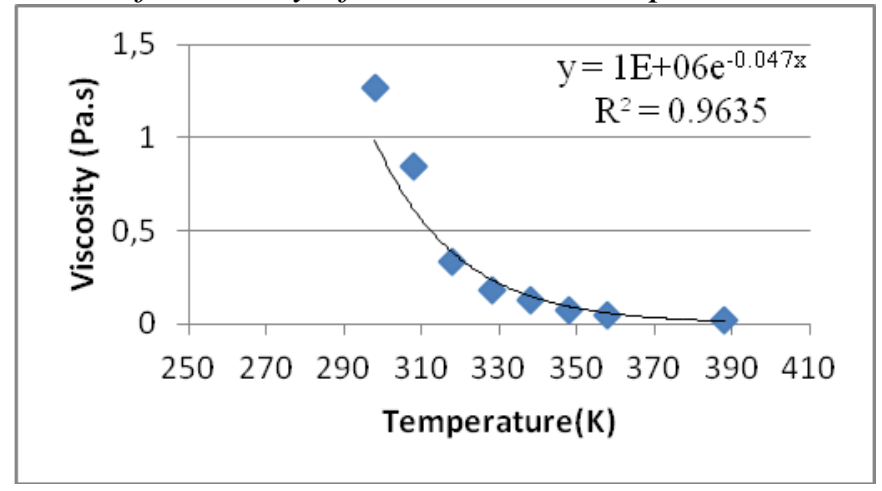

Density Measurement

The experimental values for the density of TETAL as a function of temperature from 293 to $363 \mathrm{~K}$ were measured using DE45 Mettler Toledo density meter having a precision of $\pm 0.00005 \mathrm{~g} / \mathrm{cm}^{3}$. The value of density at 
atmospheric pressure was a linear function of temperature as shown in Figure 9:

$\rho\left(\mathrm{kg} \mathrm{m}^{-3}\right)=1310.1-0.6571 \times \mathrm{T}(\mathrm{K})$

Figure 9. Density vs Temperature

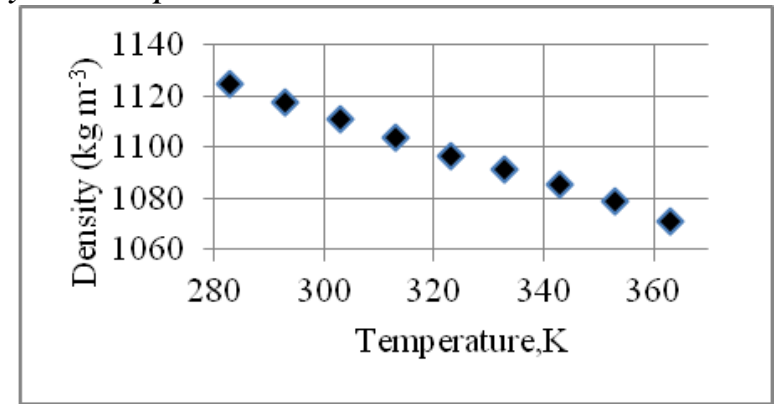

Conductivity Measurement

Conductivity measurements were carried out using Mettler Toledo conductivity meter. The instrument conductivity ranges from 0 to $2000 \mu \mathrm{S} / \mathrm{cm}$ with an accuracy of $\pm 1 \%$. Before measurements, the instrument was calibrated with $3 \mathrm{M} \mathrm{KCl}$ solution. The temperature of the sample was kept at $25 \pm 0.1^{\circ} \mathrm{C}$. Measurement was repeated three times and the average value was calculated. The measured value of ionic conductivity of TETAL under the given conditions was $0.065 \mathrm{mS} / \mathrm{cm}$.

\section{Application in Carbon Dioxide Capture}

Along with their many promising properties, the ionic liquids also present several challenges for large-scale carbon dioxide capture from flue gases. Flue gases are mainly composed of low partial pressures of carbon dioxide. The carbon dioxide solubility can be improved by tethering carbon dioxide-philic groups on ionic liquid. Another challenge is the high viscosities of the ionic liquids. The carbon dioxide absorbed ionic liquids possess even more viscous due to the formation of hydrogen bonding. As a result the absorption and desorption rates in ionic liquids becomes too slow for industrial processes.

\section{Carbon Dioxide Absorption Study}

All experiments were performed at atmospheric pressure with pure carbondioxide gas. The gas was passed through in-line $3 \mathrm{~A}^{\circ}$ molecular sieve drying tubes. The flow rate was $0.002 \mathrm{~m}^{3} \mathrm{~min}^{-1}$. Experiments were conducted in a round bottom glass reactor with an effective volume of $500 \mathrm{~cm}^{3}$. The equilibrium study of carbon dioxide absorption was conducted in a $0.7 \mathrm{M}$ solution of the ionic liquid at a temperature of $16{ }^{\circ} \mathrm{C}$ and 1 atm for 70 hours. The reactor was loaded with approximately $300 \mathrm{~cm}^{3}$ of the $0.7 \mathrm{M}$ ionic-liquid solution. The reactor was then sparged with nitrogen to remove all the air above the interface of the solution before the experiment started. The vapour 
pressure of the ionic-liquid and solvent in the gas phase of the reactor was assumed to be constant, and equal to the total equilibrium pressure before the introduction of solute gas carbon dioxide to the reactor. Carbon dioxide was introduced into the reactor via a GFC mass flow controller and a carbon dioxide rota-meter. Absorption reached a thermodynamic equilibrium after a sufficient time period, corresponding to the solubility limit of the gas in the ionic liquid at that temperature. Sample about $1 \mathrm{ml}$ of the reaction mixture were taken out at regular intervals of 5 minutes and weighed. The samples were then titrated with $2 \mathrm{M} \mathrm{HCl}$ solution to analyse the carbon dioxide loading at those time intervals. The experimental setup is depicted in Figure 10.

Figure 10. Experimental Setup for $\mathrm{CO}_{2}$ Absorption. 1. $\mathrm{CO}_{2} \mathrm{Cylinder,} \mathrm{2.} \mathrm{Digital}$ Mass Flow Controller, 3. $\mathrm{CO}_{2}$ Rotameter 4. Reaction Vessel, 5. Magnetic Stirrer, 6. Gas Inlet Port, 7. Gas Outlet Port

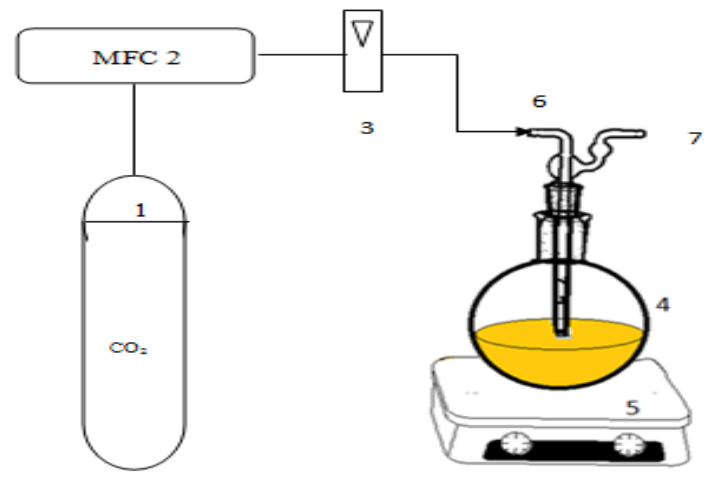

The amount of carbon dioxide absorbed in the solution was calculated assuming ideal-gas behaviour, from the following equation:

Moles of $\mathrm{CO}_{2}$ absorbed $(\alpha)=$

$$
\frac{(760-V . P \text { of water })\left(V_{\text {Fluid }}-V_{H C l}\right)}{(\text { sample of solution } \times 62.36 \times K \times 1000)}
$$

As here

$\alpha=$ Moles of $\mathrm{CO}_{2}$ absorbed (moles of $\mathrm{CO}_{2}$ /gram of ionic-liquid solution),

$\mathrm{T}=$ Room temperature $(\mathrm{K})$,

V.P.= Vapour pressure of water at room temperature $(\mathrm{mm} \mathrm{Hg})$,

$\mathrm{V}_{\text {fluid }}=$ Volume of displaced solution in the graduated tube $(\mathrm{ml})$, and

$\mathrm{V}_{\mathrm{HCl}}=$ Volume of $2 \mathrm{M} \mathrm{HCl}$ used $(\mathrm{ml})$. 
Figure 11. Carbon Dioxide Absorption in 0.7M Aqueous Solution of TETAL

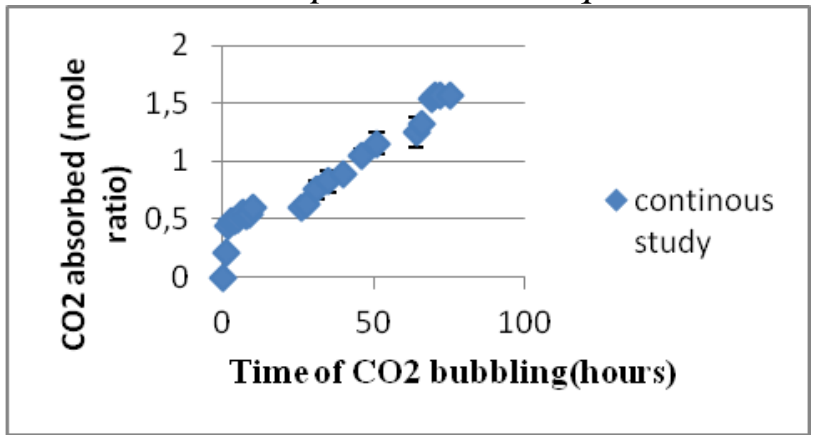

The absorption study reveals that $0.7 \mathrm{M}$ aqueous solution of TETAL can absorb up to 1.57 mole of carbon dioxide per mole of TETAL at ambient conditions as shown in Figure 11.

\section{Effect of Water on Carbon Dioxide Absorption Capacity}

The viscosity of carbon dioxide adducts which is formed upon reacting IL with carbon dioxide increases by double of the initial magnitude (Yang, 2011). The increase in viscosity is caused by the formation of a hydrogen bonding network (Wang, 2013). Due to increase in viscosity the mass transfer resistance in liquid phase is increases which limit the carbon dioxide absorption capacity of TETAL. However, small quantities of water reduce the viscosity, with some ILs having a $50 \%$ reduction in viscosity with $2 \%$ water by volume (Khupse, 2013). Ren et al. (2009) demonstrated that mainly 7\% water is present in the flue gas stream. However, the effect of water on the absorption of carbon dioxide into chemically reacting ILs has not been quantitatively reported to our knowledge. So, in this study the quantitative analysis of addition of water on absorption capacity of TETAL was done. The effect of different percentage of water addition on the rate and carbon dioxide absorption capacity of TETAL was shown in Figure 12.

Figure 12: Effect of Addition of Water on Carbon Dioxide Absorption Capacity of TETAL

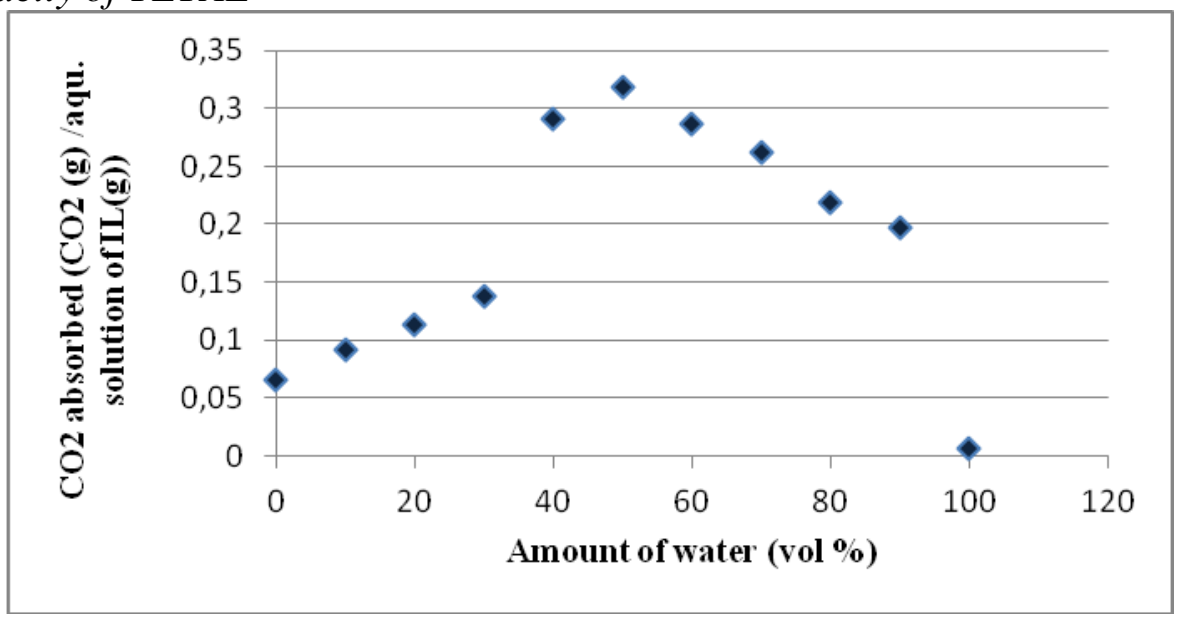


A $50 \%(\mathrm{v} / \mathrm{v})$ of water addition to TETAL increased its absorption efficiency from 0.98 to 1.56 moles carbon dioxide per mole of TETAL (Figure 12). During the carbon dioxide absorption by the ionic liquid, two basic sites get protonated which limits its absorption capacity. On adding a base, i.e. water, the extra protons from those basic sites get removed thus providing the sites for further absorption of carbon dioxide. From the quantitative analysis, it was found that addition of water up to $50 \%$ increased the absorption capacity of TETAL to a maximum of 1.56 mole/mole of TETAL, and further addition led to a decrease in the absorption capacity.

It was also found that after 70 hours of bubbling pure carbon dioxide in the reaction mixture the end product was a white precipitate. Initially, the carbamate formation predominated but the end of the absorption the product was a white precipitate which was water soluble. By wet chemistry, it was confirmed as ammonium bicarbonate. A lower energy is required to break the bicarbonate bond in comparison to the carbamate has calculated from Gaussian 03. Thus, carbon dioxide rich solvent requires less energy for regeneration.

$\mathrm{NH}_{4} \mathrm{HCO}_{3} \leftrightarrow \mathrm{NH}_{3}+\mathrm{CO}_{2}+\mathrm{H}_{2} \mathrm{O}, \quad \Delta \mathrm{H}=15.8 \mathrm{kcal} / \mathrm{mol}$

$\mathrm{RNHCOOH} \leftrightarrow \mathrm{RNH}_{2}+\mathrm{CO}_{2}, \quad \Delta \mathrm{H}=38.6 \mathrm{kcal} / \mathrm{mol}$

\section{Cost of Ionic Liquid}

The cost of an ionic-liquid solvent is obviously an important factor for its industrial applications. In general, ionic liquids are relatively very expensive in comparison to the common organic solvents used. Still, the ionic liquids are important as solvents due to their non-volatile nature and low melting points. Ionic liquids are the most expensive solvents amongst all the commercially used solvents. Basically, the cost of an ionic liquid depends on the prices of the starting materials that form the cation and anion components (Wilkes, 2002). For example, $[\mathrm{bmim}]\left[\mathrm{PF}_{6}\right],[\mathrm{bmim}]\left[\mathrm{BF}_{4}\right],[\mathrm{omim}][\mathrm{Cl}]$ used widely in carbon dioxide capture studies at lab scale are Rs 17,004.59/5g (€ 252.7), Rs 15171.40 $(€ 225.46)$, and Rs 4,660.16 (€ 69.25) per litre. The cost of these ionic liquid are very high due to the costs of source of these ions like $\mathrm{Na}\left[\mathrm{BF}_{4}\right]$ and $\mathrm{H}\left[\mathrm{PF}_{6}\right]$. The 1-alkyl-3 methylimidazolium cations are more expensive in comparison to the alkyl amines. The comparison between the cost of different cations and anions are given in the Table 2 .

Table 2. Rough Estimates of the Prices of Cation/Anion Components of Ionic Liquids

Cheap

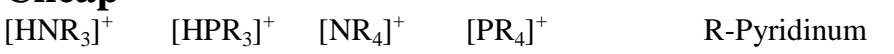

Expensive

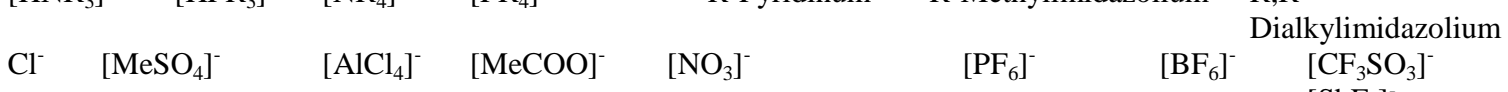

Cost of Triethylenetetramine $=$ Rs $5923.17 /$ litre 
Cost of Lactic acid $=$ Rs 5481.93/ litre

Cost of DCM = Rs 4,328 / litre

Total cost for 1 litre of ionic liquid = Rs 7145.21

The cost of 1ethyl-3methyl imidazolium bromide in conversion is Rs

1,82,562.4 /litre. These cost estimates are from Sigma Aldrich catalogue.

\section{Observations and Conclusions}

In this work we have reported the absorption capacity and physicochemical properties of TETAL. TETAL protic ionic liquid is easy to synthesize and also a low-cost ionic liquid. The carbon dioxide absorption capacity may further be enhanced by improving the basic nature of the ionicliquid which in turn can be adjusted by playing with the concentrations of acid and base used during synthesis. The carbon dioxide absorption capacity in aqueous solution of TETAL reached up to 1.57 mole of carbon dioxide absorbed /mole of TETAL. This represents the highest absorption capacity to cost ratio in comparison with all ionic liquids reported till date. This makes TETAL more attractive than all other solvents. The decomposition temperature of TETAL is $150{ }^{\circ} \mathrm{C}$. So, it has the capability of carbon dioxide absorption at a high temperature. This may be further improved in future work. In addition, substantial viscosity and density decreases have been observed with an increase in temperature, making it further attractive in practice.

\section{Acknowledgments}

We thank Chemical Engineering department, Indian Institute of Technology, Delhi, and University Grants Commission, India, for the support and funds provided for this research, including a doctoral fellowship for Amita Chaudhary.

\section{References}

Aki, S. N.V. K., Scurto, A. M., Brennecke, J. F. 2006. Ternary phase behavior of ionic liquid (IL)-organic- $\mathrm{CO}_{2}$ systems. Ind. Eng.Chem. Res., 45, 5574-5585.

Astarita, G., Savage, D. W., Bisio, A. 1983. Gas Treating with Chemical Solvents. John Wiley \& Sons, New York.

Barrosse-Antle, L. E., Compton, R. G. 2009. Reduction of carbon dioxide in 1-butyl3-methylimidazolium acetate. Chem. Commun., 3744-3746.

Bates, E. D., Mayton, R. D., Ntai, I., Davis, J. H. 2002. $\mathrm{CO}_{2}$ capture by a task-specific ionic liquid. J. Am.Chem. Soc., 124, 926-927.

Caplow, M. 1968.Kinetics of carbamate formation and breakdown. J. Am. Chem. Soc., 90, 6795-6803. 
Crooks, J. E., Donnellan, J. P. 1989. Kinetics and mechanism of the reaction between carbon dioxide and amines in aqueous solution. J. Chem. Soc. Perkin Trans., 2 , 331-333.

Danckwerts, P.V. 1979. The reaction of $\mathrm{CO}_{2}$ with ethanol amines. Chem. Eng. Sci., 34, 443-446.

Galan Sanchez, L. M., Meindersma, G. W., de Haan, A. B. 2007.Applications of taskspecific ionic liquids for intensified separations. Chem. Eng. Res. Des., 85, 3139.

Khupse, N. D., Kumar, A. 2013.Unusual salting effects in ionic liquid solutions. Indian Journal of Chemistry, 52A, 1377-1382.

Maginn, E. J. 2005. Design and Evaluation of Ionic Liquids as Novel $\mathrm{CO}_{2}$ Absorbents. DOE report, quarterly, 1-12.

Ren, R., Hou, Y., Wu, W., Chen, X., Fan, J., Zhang, J. 2009. Solubility of $\mathrm{CO}_{2}$ in amine functionalized ionic liquid. Ind. Eng. Chem. Res., 48, 4928-4932.

Scovazzo, P., Camper, D., Kieft, J., Poshusta, J., Koval, C. 2004. Regular solution theory and $\mathrm{CO}_{2}$ gas solubility in room temperature ionic liquids. Ind. Eng. Chem. Res., 43 (21), 6855-6860.

Tsuzuki, S., Shinoda,W., Saito, H., Mikami, M., Tokuda, H., Watanabe ,M.J. 2009. Molecular Dynamics Simulations of Ionic Liquids: Cation and Anion Dependence of Self-Diffusion Coefficients of Ions. Phys Chem B., 113, 1064110649.

Vaidya, P.D., Kenig, E.Y. 2007. Termolecular kinetic model for $\mathrm{CO}_{2}$-alkanolamine reactions: an overview. Chem. Eng. Technol., 33, 1577-1581.

Yokozeki, A., Shiflett, M. B., Junk, C. P., Grieco, L. M., Foo, T. 2008.Physical and Chemical Absorptions of Carbon Dioxide in Room-Temperature Ionic Liquids. $J$. Phys. Chem., 112 (51), 16654-16663.

Wang, C., Luo, H., Jiang, D., Li, H., Dai, S. 2010. Carbon dioxide capture by super base-derived protic ionic liquids. Angew. Chem. Int. Ed., 49, 5978-5981.

Wang, C., Luo, X., Zhu, X., Cui, G., Jiang, D., Deng, D., Lia, H., Dai,S. 2013. The strategies for improving carbon dioxide chemisorption by functionalized ionic liquids.RSC Advances, 3, 15518. DOI: 10.1039/c3ra42366b.

Wasserscheid, P., Welton, T. 2003. Ionic liquids in Synthesis, Wiley, Weinheim.

Wilkes, J. S. 2002. Green Chemistry, 4, 73.

Yang, Z. Z., Zhao, Y. N., He, L. N. 2011.CO $\mathrm{CO}_{2}$ chemistry: Task specific ionic liquids for $\mathrm{CO}_{2}$ capture/activation and subsequent conversion. RSC Adv., 1(4), 545-567. 